\title{
Utilization of the dethridge wheel as a low head power generator and loss analysis
}

\author{
Dan Mugisidi1,", Oktarina Heriyani ${ }^{2}$, Rizal Andi Luhung ${ }^{1}$, and Moh. Ramdani Dwi \\ Andrian ${ }^{1}$ \\ ${ }^{1}$ Mechanical Engineering, Engineering Faculty, Universitas Muhammadiyah Prof. Dr. HAMKA, \\ 12130 Jakarta, Indonesia \\ ${ }^{2}$ Electrical Engineering, Engineering Faculty, Universitas Muhammadiyah Prof. Dr. HAMKA, 12130 \\ Jakarta, Indonesia
}

\begin{abstract}
Utilization of low head flow water has long been used to generate power by using water wheels and low head turbines. Dethridge wheel which is usually used as a tool to measure the flow of water has also been studied its potential to become hydro power generation. Therefore, this study aims to compare performance between overshot Dethridge wheel and undershot Dethridge wheel. For this purpose, a small scale channel for the operation of a water wheel is equipped with a digital flow meter, a pump that has a debit of up to $25 \mathrm{l} / \mathrm{s}$, a pony brake for a torque meter, and an inverter to adjust the flow rate by changing the pump rotation. The research was conducted at Laboratory of Mechanical Engineering, UHAMKA in Jakarta, Indonesia. Flow rates vary from 5 to $11 \mathrm{l} / \mathrm{s}$ with head of $10 \mathrm{~cm}$ and $537 \mathrm{~cm}$. The efficiency of undershot and overshot, at the peak, are $21 \%$ and $18 \%$, respectively.
\end{abstract}

\section{Introduction}

Electricity is no longer a luxury for humans but has become a primary need for urban residents However, it is become different story for villagers that remote and far from the electricity supply provided by State Electricity Company (PLN). Therefore, various efforts to generate electricity independently by using the energy available in the environment continue to be done. One of energy source that is often used is hydro power. Utilization of hydro energy to generate electrical energy encourages various countries to evaluate available energy sources [1]. Numerous studies have been conducted to take advantage of the flow of water that flows. The oldest mechanical equipment used to convert water flow energy into work is a waterwheel. The waterwheel that has been used since the third century $\mathrm{BC}$, changed its function from cultivating the harvest and lifting water into a generator drive into generate electricity. With the development of technology, waterwheels that produces electricity in the low head began to be abandoned and replaced by hydraulic machines that utilize a high head to generate electricity.

\footnotetext{
* Corresponding author: oktarina@uhamka.ac.id
} 
However, because the location of high head water is limited, the utilization of water flow with low head back to the attention and Zuppinger water wheel is very suitable to produce electricity by utilizing flow on the head less than $5 \mathrm{~m}$ [2]. The flow of water with head less than $5 \mathrm{~m}$ can be found on irrigation channels. The flow of water in irrigation canals that have very low head can be utilized to generate electricity [3-6]. To utilize a water flow with very low head, such as in an irrigation stream, the Dethridge wheel, which originally used as a flow measurement, is used for electricity generation with an efficiency of $60 \%$ [7] and its performance improves in the channel width that is two to three times greater than the wheel width [8].

In this study, the Dethridge wheel is used as an electric generator driver. The water flowed will be distinguished by 2 conditions, undershot and overshot with a height of 537 $\mathrm{cm}$. Torque, rotation, and Dethridge wheel efficiency will be measured and analyzed for losses incurred in the system.

\section{Experimental set up}

Shape and dimension of the wheel and the shroud in this experiment follow the detail in Paudel [7] but using different material. In this experiment, blade and side hub use wood coated with waterproof material. The experimental rig contains artificial channel, pump with capacity $25 \mathrm{l} / \mathrm{s}$, flow meter, rotation meter, torque meter and water tank as can be seen in figure 1.

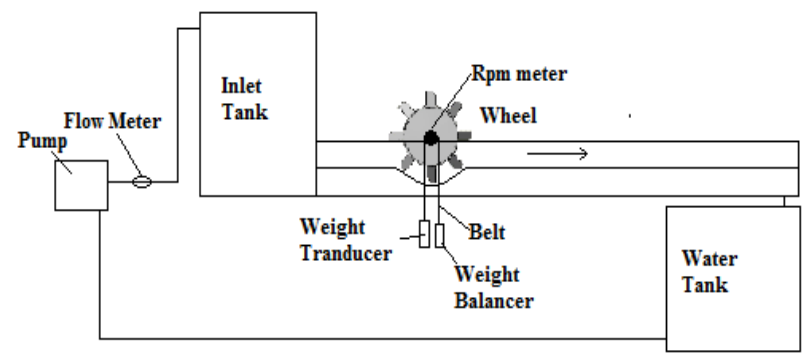

Fig. 1. Schematic of experimental rig.

Dethridge wheel rotation is measured using rotation meter while torque is measured using pony brake. At artificial canal side, before and after the dethridge wheel, are given holes that covered with acrylic sheets and mounted a height meters for manually high-water readings. Water discharges are made varying from $5 \mathrm{l} / \mathrm{s}$ to $18 \mathrm{l} / \mathrm{s}$. The torque is calculated using the weight difference between the weight balancer and the measured weight on the weight tranducer multiplied by the radius of shaft. The total head is calculated using

$$
H=\left(h_{1}+\frac{v_{1}^{2}}{g}\right)-\left(h_{1}+\frac{v_{2}^{2}}{g}\right)
$$

Power input $\left(\mathrm{P}_{i n}\right)$ is calculated using equation

$$
H P_{\text {in }}=Q \cdot \rho \cdot g \cdot H
$$

The power output $\left(\mathrm{P}_{\text {out }}\right)$ is calculated using rotation $(N)$ dan torque $(\tau)$

The efficiency $(\eta)$ is calculated using

$$
P_{\text {out }}=\frac{2 \cdot \pi \cdot N \cdot \tau}{60}
$$

$$
\eta=\frac{P_{\text {out }}}{P_{\text {in }}}
$$




\section{Result and Discussion}

In this experiment, water is delivered by the pump through the Dethridge wheel. Water pushes the Dethridge wheel blade which partially submerged in water. The result can be seen in Table 1.

Table 1. Experimen result of rotation, torque and water level overshot. US $=$ Undershot, OS $=$ Overshot.

\begin{tabular}{|r|r|r|c|c|c|}
\hline \multirow{2}{*}{$\begin{array}{c}\text { Flow } \\
\text { rate } \\
{[\boldsymbol{l} \mathbf{s}]}\end{array}$} & \multirow{2}{*}{$\begin{array}{c}\text { Water } \\
\text { Level } \\
\text { overshot } \\
{[\mathbf{c m}]}\end{array}$} & \multicolumn{2}{|c|}{$\begin{array}{c}\text { Rotation } \\
{[\mathbf{R p m}]}\end{array}$} & \multicolumn{2}{|c|}{$\begin{array}{c}\text { Torque } \\
{[\mathbf{N m}]}\end{array}$} \\
\cline { 3 - 7 } & $\mathbf{U S}$ & OS & US & OS \\
\hline 5 & 6,5 & 4,88 & 17,13 & 0,68 & 2,15 \\
\hline 7 & 8 & 9,30 & 31,46 & 0,69 & 1,82 \\
\hline 9 & 9 & 10,27 & 58,21 & 0,73 & 1,02 \\
\hline 11 & 10 & 11,73 & 49,34 & 0,77 & 1,01 \\
\hline
\end{tabular}

Dethridge wheel rotation is influenced by the amount of water that flows, as can be seen in Figure 2 Rotation of Dethridge wheel, undershot and overshot accelerate with increasing flow of water. However, on the overshot wheel, rotation of the Dethridge wheel decrease at a $11 \mathrm{l} / \mathrm{s}$ due to the water before the Dethridge wheel hold the wheel back. Such conditions also affect the torque as can be seen in Fig 3 .

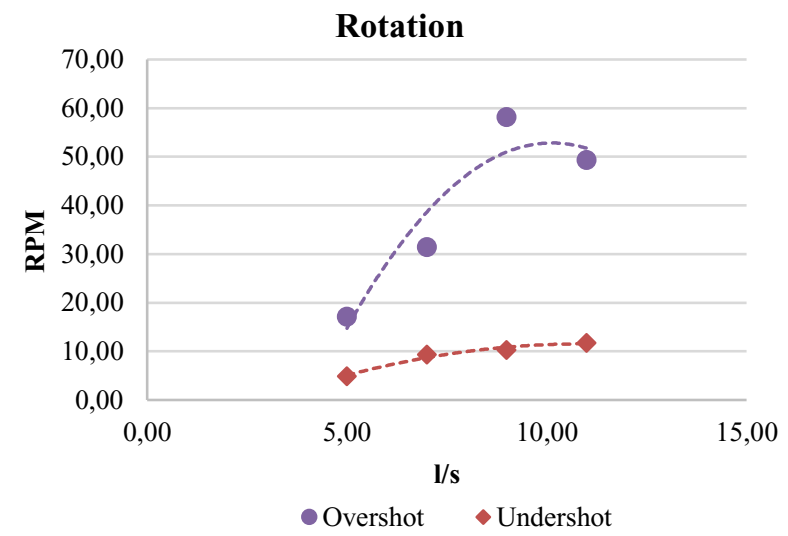

Fig. 2. Rotation of overshot and undershot dethridge wheel.

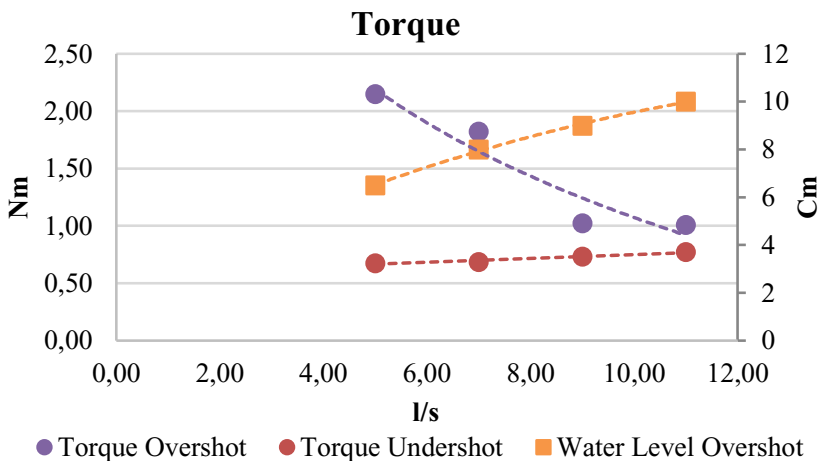

Fig. 3. Torque undershot, overshot, and water level of overshot. 
On the undershot Dethridge wheel, torque improves as the flow rate increases. That situation did not happen to Overshot Dethridge wheel. The torque generated by the Overshot Dethridge wheel decreases as the flow rate is increased, while the water retained before the Dethridge wheel continues to increase. These result do not match the estimated torque.

Table 2. Overshot Prediction Torque

\begin{tabular}{|r|c|c|c|}
\hline $\begin{array}{c}\text { mass } \\
{[\mathbf{k g} / \mathbf{s}]}\end{array}$ & $\begin{array}{c}\text { Water } \\
\text { Velocity } \\
{[\boldsymbol{m} / \mathbf{s}]}\end{array}$ & $\begin{array}{c}\text { Blade } \\
\text { radius } \\
{[\boldsymbol{m}]}\end{array}$ & $\begin{array}{c}\text { Overshot } \\
\text { prediction } \\
\text { torque } \\
{[\mathbf{N m}]}\end{array}$ \\
\hline 5 & 2,43 & 0,25 & 3,0375 \\
\hline 7 & 2,43 & 0,25 & 4,2525 \\
\hline 9 & 2,43 & 0,25 & 5,4675 \\
\hline 11 & 2,43 & 0,25 & 6,6825 \\
\hline
\end{tabular}

The estimated torque on the overshot Dethridge wheel that shown in Table 2 shows that the torque increases with increasing flow rate. Increasing flow rates cause the falling water mass to hit the blade also becomes larger. Therefore the force that drives the blade will also become larger. The results do not match the test results. The water that retained before Dethridge wheel causes the water force obtained from water that fall into the blade decrease because to overcome the reaction force that arises in water. The blades that have been in the water, must push the water between the blades, therefore the torque generated by the Dethridge wheel is decreasing.

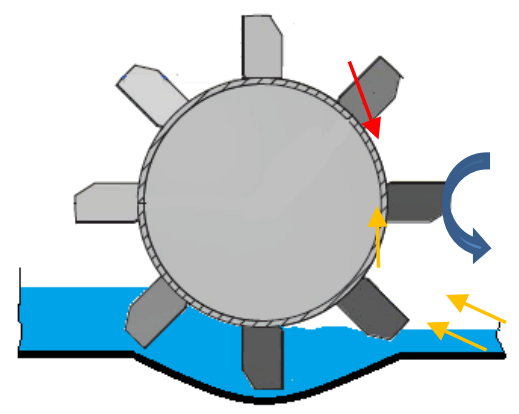

Fig. 4. Schematic of force that workon the Dethridge wheel. Red arrow = water force, yellow arrow = water reaction force.

Using rotation and torque obtained from Dethridge wheel rotation, then power can be estimated by using equation 3. The result can be seen in Figure 5. Power of undershot Dethridge wheel range from 0,35 to $0,95 \mathrm{watt}$, which increases due to an increase in flow rate. Power of overshot Dethridge wheel ranged from the power generated by the overshot dethridge wheel is much higher than the undershot dethridge wheel. Since the force from the mass falling into the blade is much greater than the water thrust force on the undershot dethridge wheel, the resulting rotation and torque are also much larger. Based on the estimated power generated by the overshot and undershot Dethridge wheel, then its efficiency can be calculated, as shown in Figure 6. 


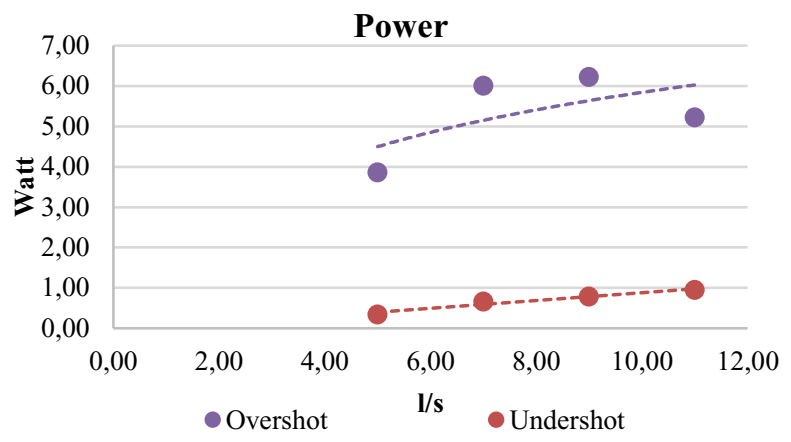

Fig. 5 Power generated of overshot and undershot Dethridge wheel.

As we can see in Figure 6, the efficiency of overshot and undershot Dethridge wheel has a similar patern. The peak of the efficiency in both types of water entry is $7 \mathrm{l} / \mathrm{s}$. The efficiency of undershot and overshot, at the peak, are $21 \%$ and $18 \%$, respectively. Eventhough the power generated by the overshot Dethridge wheel is greater than that of the undershot Dethridge wheel, the losses to be owed by the overshot Dethridge wheel are much bigger. Kinetic energy possessed by water comes out of the system without doing work. Furthermore, the great power losses are the friction of the kinetic energy of the flow against the blade and the hydraulic loss in the headrace and canal bed [9].

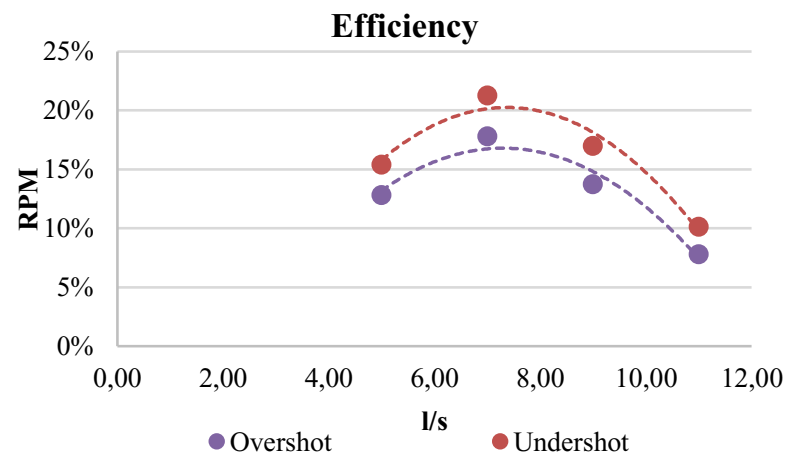

Fig. 6. Efficiency of overshot and undershot Dethridge wheel.

\section{References}

1. N.D. Laws, B.P. Epps, Hydrokinetic energy conversion: Technology, research, and outlook, Renew. Sustain. Energy Rev. 57, 1245-1259 (2016)

2. S. Paudel, M. Weber, D. Geyer, N. Saenger, Zuppinger Water Wheel for Very LowHead Hydropower Application, in: Mar. Hydro Power, 2017: pp. 25-34.

3. A. Botto, P. Claps, D. Ganora, F. Laio, Regional-scale assessment of energy potential from hydrokinetic turbines used in irrigation channels, in: SEEP 2010 Conf. Proc., 2010: pp. 1-7.

4. T. UEDA, M. GOTO, A. Namihira, Y. HIROSE, Perspectives of Small-scale Hydropower Generation Using Irrigation Water in Japan, JARQ. 47 (2013) 135-140.

5. D. Gensler, K.-D. Kinzli, J. Irrig. Drain. Eng. 139 (2013) 405-413.

6. D. Antonio Zema, A. Nicotra, V. Tamburino, S. Marcello Zimbone, A simple method 
to evaluate the technical and economic feasibility of micro hydro power plants in existing irrigation systems, (2016). doi:10.1016/j.renene.2015.06.066.

7. S. Paudel, N. Saenger, Earth Environ. Sci. 49 (2016)

8. S. Paudel, N. Saenger, Renew. Energy, (2017)

9. E. Quaranta, R. Revelli, Energy, 87, 315-325 (2015) 